\title{
TWO NEW SPECIES OF XARIFIA HUMES, 1960 (COPEPODA, XARIFIIDAE) ASSOCIATED WITH CORALS OF TAIWAN
}

\author{
BY \\ YU-RONG CHENG ${ }^{1,3}$ ), JU-SHEY HO ${ }^{2}$ ) and CHANG-FENG DAI ${ }^{1}$ ) \\ ${ }^{1}$ ) Institute of Oceanography, National Taiwan University, No. 1 Roosevelt Road, Section 4, Taipei \\ 106, Taiwan \\ ${ }^{2}$ ) Department of Biological Sciences, California State University, 1250 Bellflower Boulevard, \\ Long Beach, California 90840-3702, U.S.A.
}

\begin{abstract}
Two new species of copepods of the genus Xarifia Humes, 1960 (Poecilostomatoida, Xarifiidae) associated with scleractinian corals of Taiwan are described. They are: $X$. insolita $\mathrm{n}$. sp. from Tubastraea aurea (Quoy \& Gaimard, 1833) and X. longa $\mathrm{n}$. sp. from Porites latistella Quelch, 1886. The former species is characteristic in having 2 spines on the third segment of legs 1-4. The latter species has a combination of the following features : region dorsal to fifth legs with 3 long, equally long, posteriorly directed processes; long caudal ramus; an armature of 3, 22 +1 aesthetascs, $2+1$ aesthetascs on the antennule; and each of the first two segments of the maxilliped with 2 round protrusions.
\end{abstract}

\section{RÉSUMÉ}

Deux espèces nouvelles de copépodes du genre Xarifia Humes, 1960 (Poecilostomatoida, Xarifiidae) associés aux coraux scléractiniaires de Taiwan sont décrites. Ce sont: X. insolita n. sp. associé à Tubastraea aurea (Quoy \& Gaimard, 1833) et X. longa n. sp. associé à Porites latistella Quelch, 1886. La première espèce est caractéristique par la présence de 2 épines sur le troisième segment des pattes 1-4. La seconde présente une combinaison des caractères suivants : région dorsale jusqu'aux cinquièmes pattes avec 3 longs processus, dirigés postérieurement et de même longueur; rames caudales longues, armature de 3,22+1 aesthétasques, $2+1$ aesthétasques sur l'antennule; et chacun des deux premiers segments du maxillipède pourvu de protubérances arrondies.

\section{INTRODUCTION}

Many animals are commonly found living in association with corals. Among these associates are xarifiid copepods that live in the gastrovascular cavities of

3) e-mail: jsho@csulb.edu 
scleractinian polyps. According to Humes (1985), xarifiids, comprising 79 species in four genera, are widely distributed in the tropical Indo-Pacific region with an apparent absence from the central and eastern Pacific. Xarifia Humes, 1960 is the largest genus of the Xarifiidae Humes, 1960 (Poecilostomatoida) containing 75 species with most of them recorded from the Indian Ocean and the southern Pacific (Humes, 1985). So far, only eight species of Xarifia are known from the northern hemisphere in the Pacific, two species from Japan (Misaki, 1978) and seven species from Eniwetok (Humes, 1985). In this paper we report two new xarifiid copepods found on corals collected from Nanwan Bay in southern Taiwan.

\section{MATERIALS AND METHODS}

Samples (either fragments or whole colonies) of scleractinian corals were collected with SCUBA diving, placed in a separate bag while in the water, and transported to the laboratory for examination of copepod parasites. To collect xarifiids, the coral together with the sea water in the bag was emptied into a bucket to which sufficient $95 \%$ ethyl alcohol was added to make it approximately a 5\% solution. After several hours, the copepods would leave the coral polyps, and then fell to the bottom of the container. Then the water was poured through a fine net (mesh size approximately $100 \mu \mathrm{m}$ ). The copepods were picked from the sediment retained in the net and preserved in $70 \%$ ethanol. They were later cleared in $85 \%$ lactic acid for 1 to $2 \mathrm{~h}$, then dissected on a wooden slide under a dissecting microscope (Humes \& Gooding, 1964). The removed body parts and appendages were examined under a compound microscope with a series of magnifications up to $1000 \times$. All drawings were made with the aid of a camera lucida.

\section{SYSTEMATIC ACCOUNTS}

Xarifiidae Humes, 1960

Xarifia Humes, 1960

Xarifia insolitus n. sp. (figs. 1-3)

Material examined. - Five at $6 \mathrm{~m}$ depth, at Houbihu, Pingtung, southern Taiwan on 16 August 2006; 2 o 9 from the same species of host collected at $4 \mathrm{~m}$, at Tiaoshi, Pingtung, southern Taiwan on 25 November 2006. Holotype (NTUIO-COPEPOD 0001), allotype (NTUIO-COPEPOD 0002), and 3 paratypes (NTUIOCOPEPOD 0003) deposited in the Institute of Oceanography, National Taiwan University, Taipei, Taiwan.

Female. - Body (fig. 1A, B) moderately slender. Length $2.36(2.30-2.41) \mathrm{mm}$ and greatest width $0.48(0.42-0.52) \mathrm{mm}$, based on 3 specimens. Segmentation of 
A

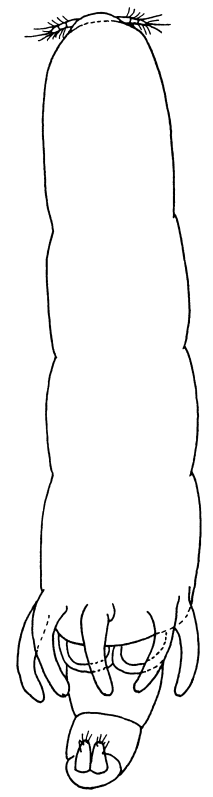

$\mathbf{F}$

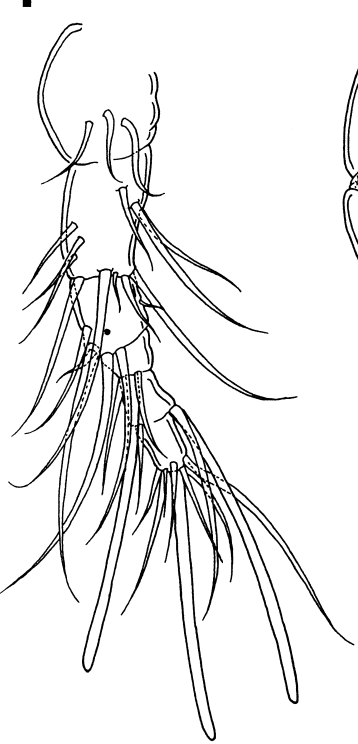

$\mathbf{G}$
B

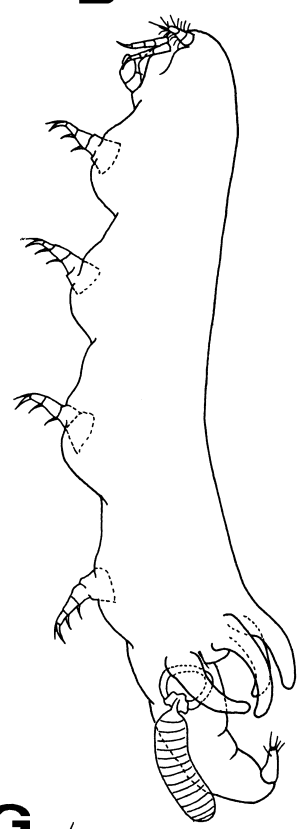

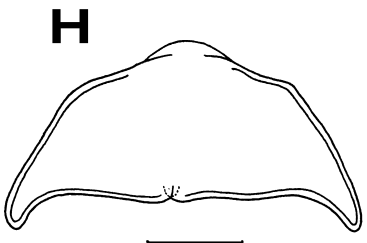
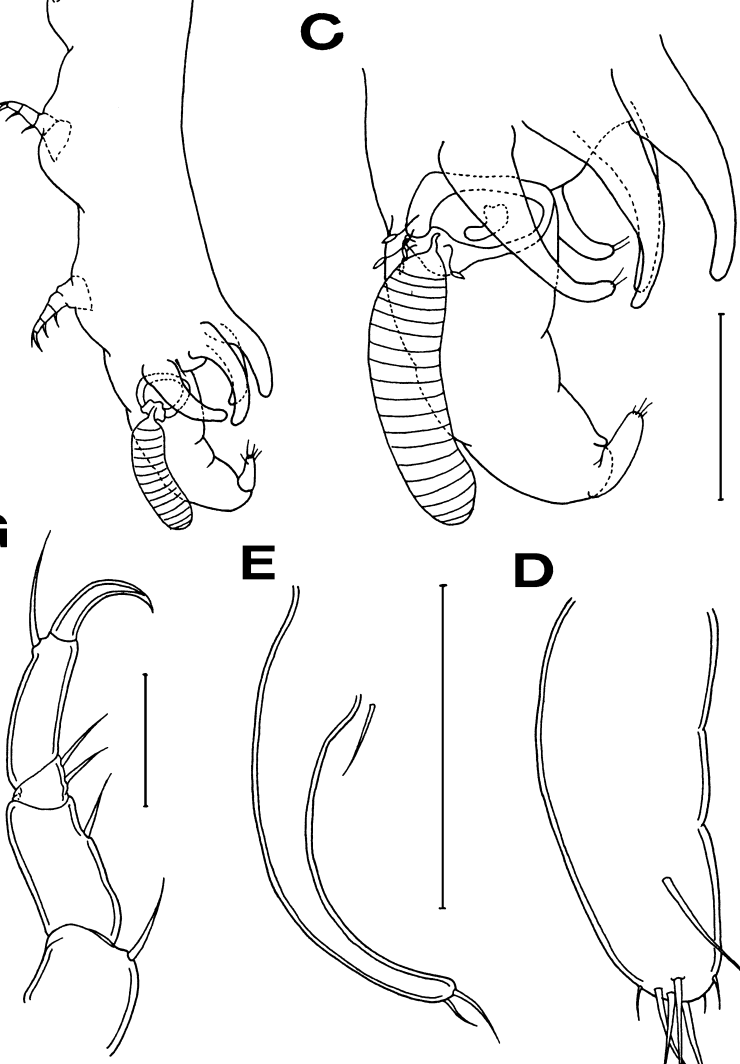

$\mathbf{E}$

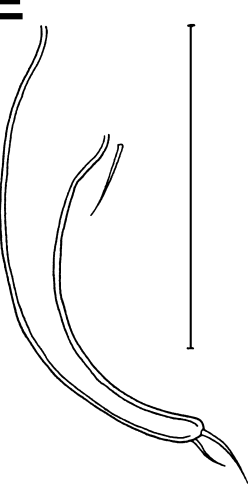

D
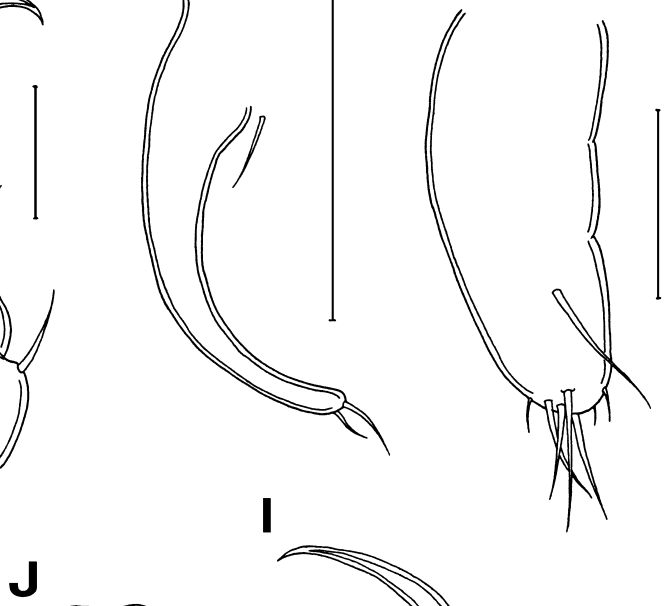

I
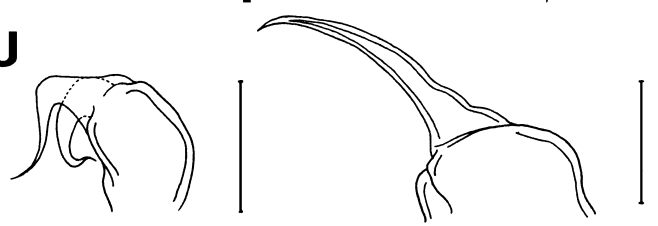

Fig. 1. Xarifia insolita n. sp., female paratype. A, habitus, dorsal; B, habitus, lateral; C, processes and urosome, lateral; D, caudal ramus, dorsal; E, leg 5, dorsal; F, antennule, with dot indicating position of aesthetasc in male; G, antenna, anterior; H, labrum, ventral; I, mandible, ventral; J, maxillule, anterior. Scale bar: $0.5 \mathrm{~mm}$ in $\mathrm{A}$ and $\mathrm{B} ; 0.25 \mathrm{~mm}$ in $\mathrm{C}$ and $\mathrm{E} ; 0.05 \mathrm{~mm}$ in $\mathrm{D}, \mathrm{G}$, and $\mathrm{H} ; 0.02 \mathrm{~mm}$ in $\mathrm{F}$, I, and J. 
A
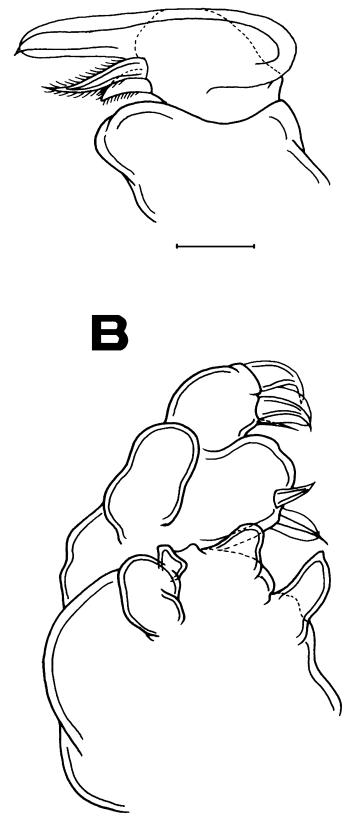

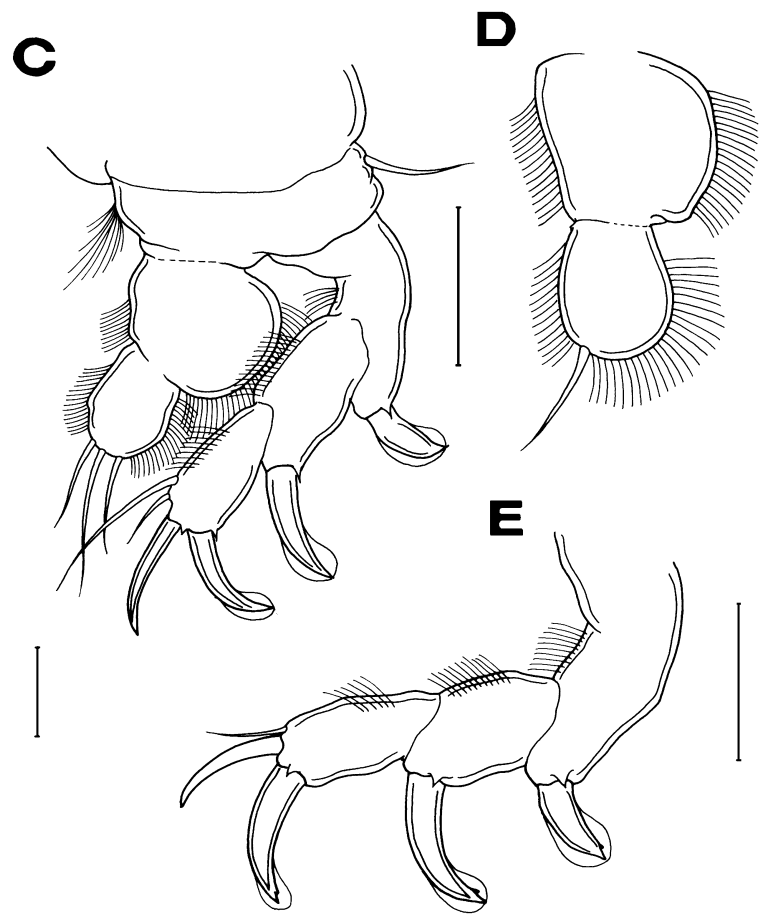

Fig. 2. Xarifia insolita $\mathrm{n}$. sp., female paratype. A, maxilla, anterior; B, maxilliped, posterior; C, leg 1, anterior; D, endopod of leg 3, anterior; E, exopod of leg 4, anterior. Scale bar: $0.02 \mathrm{~mm}$ in A and $\mathrm{B} ; 0.05 \mathrm{~mm}$ in $\mathrm{C}, \mathrm{D}$, and $\mathrm{E}$.

body indistinct. Region dorsal to fifth legs with 3 posteriorly directed processes of similar length (fig. 1A-C). Genital and postgenital somites recurved upward. Areas of attachment of egg sacs located dorso-laterally. Egg sac empty, but seemingly having contained 18 flattened eggs in one row (fig. 1C). Caudal ramus (fig. 1D) elongate, bearing 4 terminal setae, and 1 outer, marginal seta in addition to 3 setules on posterior margin. Surface of body unornamented (fig. 1A, B).

Antennule (fig. 1F) 6-segmented; armature: 3, 11, 6, 2+1 aestheteasc, $2+1$ aesthetasc and $7+1$ aesthetasc; all setae naked. Antenna (fig. 1G) 4-segmented; armature: $1,1,2$, and $1+\mathrm{I}$.

Labrum (fig. 1H) projected posteriorly at both free corners. Mandible (fig. 1I) with a pointed, slender, smooth blade. Maxillule (fig. 1J) tipped with 2 long setae. Maxilla (fig. 2A) 2-segmented; first segment with protruded mediodistal corner; second segment with 2 plumose setae and a terminal lamellate expansion. Maxilliped (fig. 2B) 3-segmented; first segment largest, with 3 protuberances; second segment with 1 lateral process and 2 inner, spiniform setae; and third segment smallest, tipped with 2 claws and 1 seta. 
A

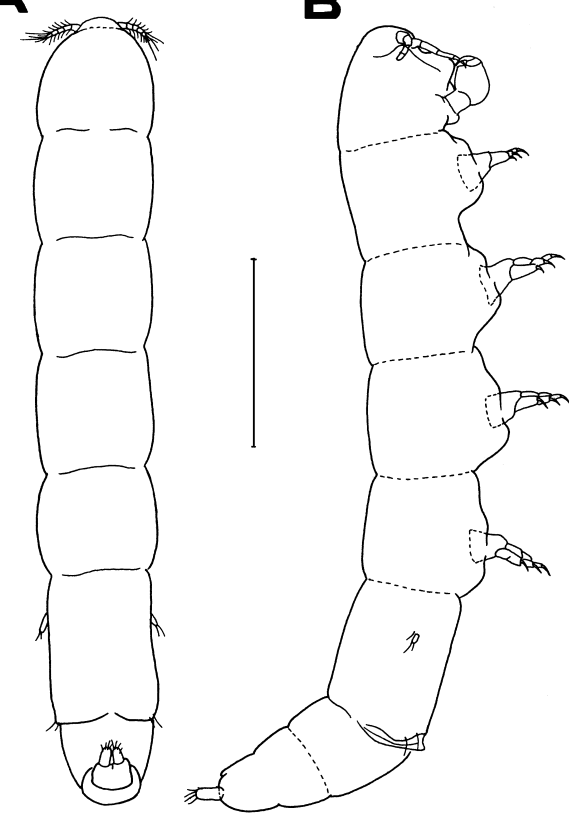

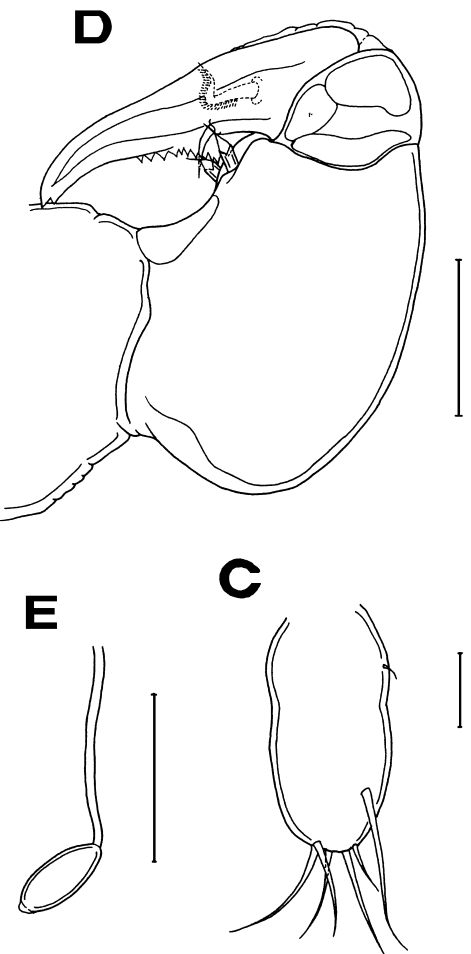

Fig. 3. Xarifia insolita n. sp., male paratype. A, habitus, dorsal; B, habitus, lateral; C, caudal ramus, lateral; D, maxilliped; E, spermatophore. Scale bar: $0.1 \mathrm{~mm}$ in A and B; $0.025 \mathrm{~mm}$ in E; $0.02 \mathrm{~mm}$ in $\mathrm{C}$.

Legs 1-4 (fig. 2C, D, E) with 3-segmented exopods and 2-segmented endopods. Spine and setal formula as follows (Arabic numerals indicate setae; Roman numerals indicate spines):

$\begin{array}{lcccc} & \text { Coxa } & \text { Basis } & \text { Exopod } & \text { Endopod } \\ \text { Leg 1 } & 0-0 & 1-0 & \text { I-0; I-0; I,I,2 } & 0-0 ; 3 \\ \text { Leg 2 } & 0-0 & 1-0 & \text { I-0; I-0; I,I,2 } & 0-0 ; 3 \\ \text { Leg 3 } & 0-0 & 1-0 & \text { I-0; I-0; I,I,1 } & 0-0 ; 1 \\ \text { Leg 4 } & 0-0 & 1-0 & \text { I-0; I-0; I,I,1 } & 0-0 ; 1\end{array}$

Each exopodal segment with spiniform protrusion at base of outer spine. All spines on exopods with lamella at tip except inner spine on terminal segment.

Leg 5 (fig. 1E) elongate and tapering distally; with 2 unequal, terminal setae and adjacent dorsal seta.

Male. - Body (fig. 3A, B) slender, with abdominal region arched upward. Length $2.08(1.98-2.18) \mathrm{mm}$ and greatest width $0.37(0.35-0.39) \mathrm{mm}$, based on 
2 specimens. Caudal ramus (fig. 3C) elongate, bearing 4 terminal setae, 1 outer, subterminal seta, and 2 setules ( 1 basal and the other terminal).

Antennule, antenna, mandible, maxillule, and maxilla like those of female, but 1 aesthetasc added to second segment of antennule (at point indicated by a dot in fig. 1F). Maxilliped (fig. 3D) 4-segmented; first and third segments unarmed; second segment with 2 spiniform, inner setae; fourth segment a claw with bifid tip, bearing 2 proximal setae and a row of teeth in middle region of concave surface.

Legs 1-4 as in female. Leg 5 (fig. 3A, B) a small, unornamented free segment carrying 2 terminal setae and an adjacent dorsal seta. Leg 6 (fig. 3A, B) represented by 2 small setae on posteroventral flap on genital somite.

Spermatophore (fig. 3E) elongated and pyriform.

Etymology. - The species name insolita stands for several unusual structures found in the present species. It is an adjective agreeing in gender with the (feminine) generic name.

Remarks. - The new species can be easily distinguished from its congeners by the presence of 2 spines on the third (terminal) exopodal segment of legs 14. Another unusual feature is the possession of an outer spine with lamella at the tip of each segment of the exopod in both sexes. These features are unique to the present new species. The true nature of the egg sac of this species is unknown. However, if it is a uniseriate egg sac, like the empty sac that we found in one of our female specimens, then this characteristic is another distinguishing feature of the new species.

Xarifia longa n. sp. (figs. 4-6)

Material examined. - Six 우, $5 \sigma^{7} \sigma^{7}$ from Porites latistella Quelch, 1886 collected at $8 \mathrm{~m}$ depth, at the outlet of the Third Nuclear Power Plant, Pingtung, southern Taiwan, on 1 April 2005. Holotype (NTUIO-COPEPOD 0004), allotype (NTUIO-COPEPOD 0005), and 2 paratypes (NTUIO-COPEPOD 0006) deposited in Institute of Oceanography, National Taiwan University, Taipei, Taiwan.

Female. - Body (fig. 4A, B) elongate. Length 1.187 (1.183-1.193) mm and greatest width $0.187(0.183-0.190) \mathrm{mm}$, based on 3 specimens. Segmentation of body indistinct. Region dorsal to fifth legs with 3 posteriorly directed processes of similar length (fig. 4A, B). Genital and postgenital somites curved upward (fig. 4B). Areas of attachment of egg sacs located dorsally. Egg sacs not seen. Caudal ramus (fig. 4C) elongate, bearing 3 terminal setae and 1 outer marginal seta. Surface of body unornamented (fig. 4A, B).

Antennule (fig. 4E) 4 or 5-segmented, armature: 3, 11, $11+1$ aesthetasc, $2+1$ aesthetasc, and $7+1$ aesthetasc. All setae naked. Segmentation and armature of antenna (fig. 4F) as in previous species. 


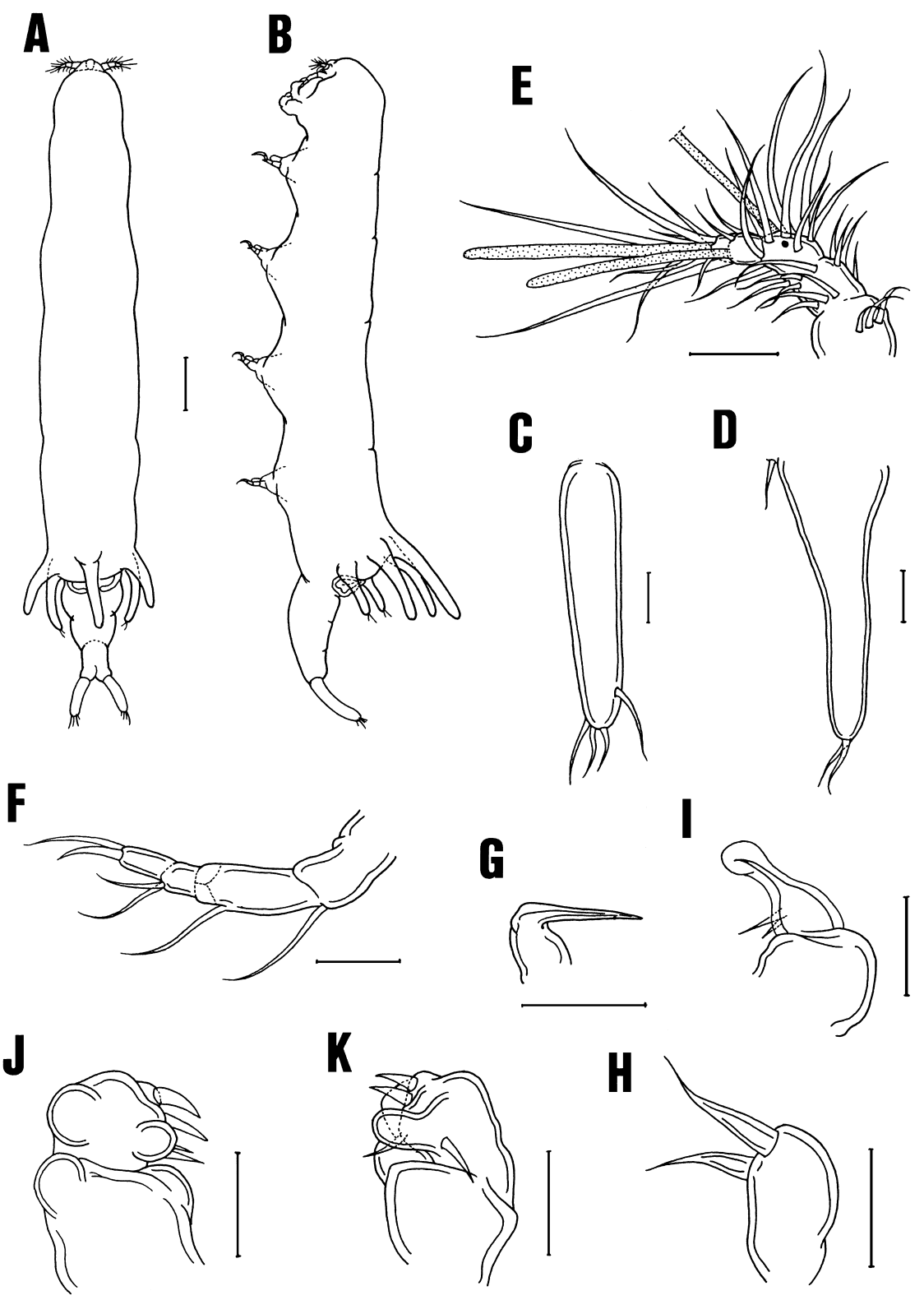

Fig. 4. Xarifia longa n. sp., female paratype. A, habitus, dorsal; B, habitus, lateral; C, caudal ramus, lateral; D, leg 5, dorsal; E, antennule, with dot indicating position of aesthetasc in male; $\mathrm{F}$, antenna, anterior; G, mandible, ventral; H, maxillule, anterior; I, maxilla, anterior; J, maxilliped, posterior; K, maxilliped. Scale bar: $0.1 \mathrm{~mm}$ in A and B; $0.02 \mathrm{~mm}$ in C, D, E, F, G, H, I, J, and K. 
A

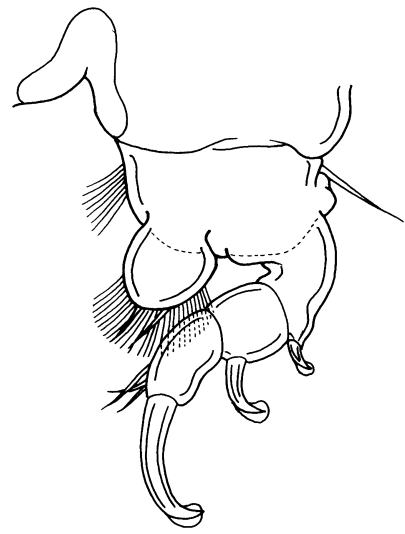

B

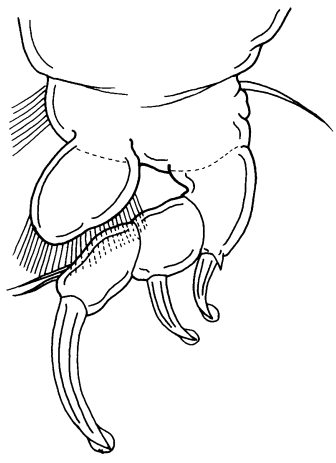

Fig. 5. Xarifia longa n. sp., female paratype. A, leg 1, anterior; B, leg 3, anterior. Scale bar: $0.02 \mathrm{~mm}$.

A

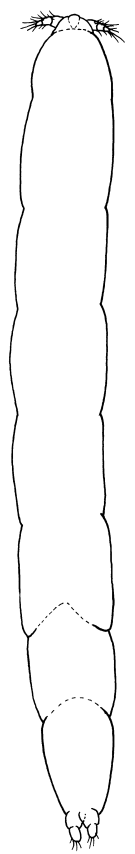

B

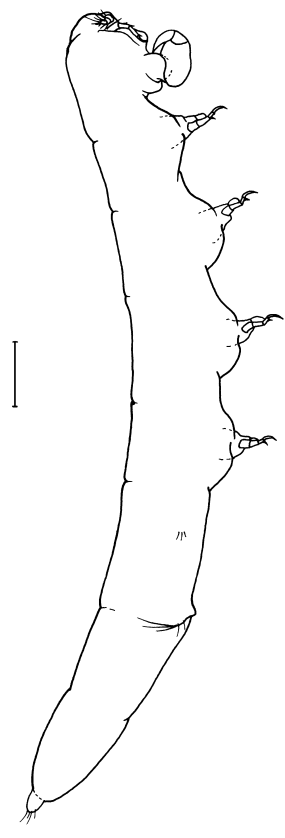

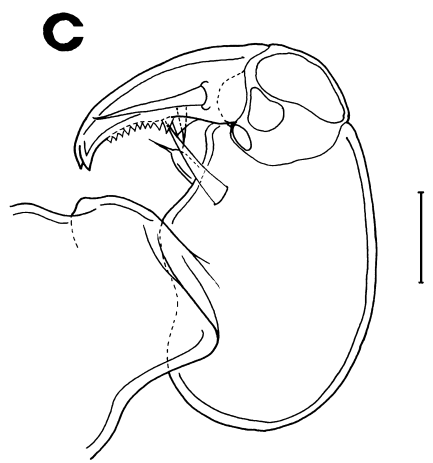

Fig. 6. Xarifia longa n. sp., male paratype. A, habitus, dorsal; B, habitus, lateral; C, maxilliped, posterior. Scale bar: $0.1 \mathrm{~mm}$ in A and B; $0.02 \mathrm{~mm}$ in C.

Mandibular blade (fig. 4G) smooth and pointed. Maxillule (fig. 4H) with 2 long terminal setae. Maxilla (fig. 4I) 2-segmented; first segment unarmed; second segment with 2 basal setae and elongate tip with lamellate expansion. Maxilliped 
(fig. 4J, K) 3-segmented; first segment with 2 round swellings; second segment with 2 inner setae and 2 round swellings; small terminal segment with 2 claws.

Legs 1-4 (fig. 5A, B) with 3-segmented exopods and 1-segmented endopods. Spine and setal formula as follows (Arabic numerals indicate setae; Roman numerals indicate spines):

$\begin{array}{lcccc} & \text { Coxa } & \text { Basis } & \text { Exopod } & \text { Endopod } \\ \text { Leg 1 } & 0-0 & 1-0 & \text { I-0; I-0; I,3 } & 2 \\ \text { Leg 2 } & 0-0 & 1-0 & \text { I-0; I-0; I,3 } & 2 \\ \text { Leg 3 } & 0-0 & 1-0 & \text { I-0; I-0; I,2 } & 0 \\ \text { Leg 4 } & 0-0 & 1-0 & \text { I-0; I-0; I,2 } & 0\end{array}$

Leg 5 (fig. 4D) elongate, with 2 terminal setae and adjacent dorsal seta.

Male. - Body (fig. 6A, B) slender and slightly arched. Length 1.243 (1.234$1.243) \mathrm{mm}$ and greatest width $0.168(0.163-0.173) \mathrm{mm}$, based on 2 specimens. Caudal ramus as in female.

Antennule, antenna, mandible, and maxillule like those of female, but 1 aesthetasc added to second segment of antennule (at point indicated by a dot in fig. 4E). Maxilliped (fig. 6C) 4-segmented; first and third segments unarmed; second segment robust, with 2 inner setae; fourth segment a claw with bifid tip, bearing 2 unequal, proximal setae and a row of teeth in middle region of concave surface.

Legs 1-4 as in female. Leg 5 comprising 3 small setae on lateral side of fused $5^{\text {th }}$ pediger and genital somite (see fig. 6B). Leg 6 (fig. 6B) represented by 2 small setae on posteroventral flap on genital somite.

Etymology. - The species name longa, Latin meaning long, alludes to its long caudal ramus which is a typical structure of this species. The name thus is an adjective agreeing in gender with the (feminine) generic name.

Remarks. - Five species of Xarifia have the formula 2, 2, 0,0 for the terminal armature of the endopods of legs 1-4 as in X. longa. They are X. anopla Humes \& Dojiri, 1982, X. brevicauda Humes \& Ho, 1968, X. filata Humes, 1985, X. hadra Humes \& Dojiri, 1983, and X. scutipes Humes \& Dojiri, 1983. However, they are readily distinguished from $X$. long $a$ by the structure of the maxilliped in the female. While each of the first two segments of the maxilliped in the present species bears 2 round swellings (see fig. $4 \mathrm{~J}$ ), it is constructed unlike that in the five congeners mentioned. Furthermore, $X$. anopla lacks knobs or processes above the fifth legs in the female (Humes \& Dojiri, 1982); the females of X. brevicauda and X. hadra have fused genital and postgenital somites (Humes \& Ho, 1968; Humes \& Dojiri, 1983); X. filata has an outer, proximal, thumb-like process at the second segment of the maxilla in both sexes (Humes, 1985); and leg 5 in female $X$. scutipes is a large lamella (Humes \& Dojiri, 1983). 


\section{ACKNOWLEDGEMENTS}

We thank Shang-Yin Liu, Ming-Jay Ho, Anyi Cheng, Sharon Horng, TsaiMing Lu, and Cheing-hwa Huang for their assistance in the field. This study was partially supported by a grant from the National Science Council and the Fisheries Administration of the Council of Agriculture in Taiwan. Completion of the manuscript of this paper was aided by a grant from the Paramitas Foundation to J.S.H.

\section{REFERENCES}

Humes, A. G., 1985. A review of the Xarifiidae (Copepoda, Poecilostomatoida), parasites of scleractinian corals in the Indo-Pacific. Bull. mar. Sci., 36 (3): 467-632.

HumES, A. G. \& M. DoJIRI, 1982. Xarifiidae (Copepoda) parasitic in Indo-Pacific scleractinian corals. Beaufortia, 32: 139-228.

_, 1983. Copepoda (Xarifiidae) parasitic in scleractinian corals from the Indo-Pacific. Journ. nat. Hist., London, 17: 257-307.

Humes, A. G. \& R. U. Gooding, 1964. A method for studying the external anatomy of copepods. Crustaceana, 6: 238-240.

Humes, A. G. \& J. S. Ho, 1968. Xarifiid copepods (Cyclopoida) parasitic in scleractinian corals from the Indo-Pacific. Bull. Mus. comp. Zool., Harvard, 136: 415-459.

MisAKI, H., 1978. Two new species of Xarifia (Copepoda, Cyclopoida) parasitic on the coral Acropora pectinata at Sabiura. Bull. mar. Park Res. Sta., 2: 105-114. 